\title{
Tres términos warburgianos para acercarse a la literatura comparada
}

\section{Three Warburgian Terms to Approach Comparative Literature}

\author{
SANDRA ÁLVAREZ HERNÁNDEZ \\ Facultad de Filosofía y Letras \\ UNIVERSIDAD NAGIONAL AUTÓNOMA DE MÉxiCO | México \\ Contacto: sandraalvarez@filos.unam.mx
}

\section{Resumen}

La tarea de comparar es indispensable en todo tipo de investigación académica, pues exige la elección de un tema de estudio y de un grupo de criterios cuyo encuentro sea capaz de formar nuevo conocimiento. La comparatística es parte natural de la filosofía, las artes visuales, la sociología y la historia, entre otras disciplinas. Hoy en día la literatura comparada se acerca más a los estudios culturales comparados; por lo tanto, esta nueva disciplina requiere de una metodología que apele al multiculturalismo y la interdisciplinariedad a fin de sentar las bases para una literatura comparada del futuro. Los estudios culturales forman parte de disciplinas de reciente creación a partir de los cambios que el siglo XIX trajo a la literatura, la historia y las artes. Una de ellas es la línea de estudios iniciada por Aby Warburg y que en fechas recientes ha pasado por un refrescante renacimiento. En 1929, cuando Warburg murió súbitamente, su trabajo quedó inconcluso en manos de sus alumnos que se dedicaron (lo siguen haciendo) a continuarlo. Desde entonces, investigaciones como las pertenecientes al área de Historia del Arte han hecho uso de su metodología. Sin embargo, considero que es posible encontrar dentro de los mismos conceptos warburgianos una metodología que ayude a trabajar den- 
tro de los nuevos alcances de la literatura comparada. Los términos Nachleben, Denkraum y Umfangsbestimmung ayudarán a formar esta propuesta.

\title{
Palabras clave
}

Warburg, Nachleben, Denkraum, Umfangsbestimmung, literatura comparada

\begin{abstract}
Comparison is indispensable in all types of academic research, since it requires the choice of a topic of study and a group of criteria capable of forming new knowledge. Comparatism is a natural part of philosophy, visual arts, sociology, and history, among other disciplines. Nowadays comparative literature is closer to comparative cultural studies; therefore, this new discipline requires a methodology that appeals to multiculturalism and interdisciplinarity to lay the foundations for a comparative literature of the future. The changes that the nineteenth century brought to literature, history, and the arts created a series of disciplines that include cultural studies. One of them is the line initiated by Aby Warburg, which has recently experienced a refreshing renaissance. In 1929, when Warburg suddenly died, his work was left unfinished in the hands of his students, who dedicated themselves (and still do) to continue it. Since then, investigations such as those belonging to the area of Art History have made use of its methodology. However, I believe that it is possible to find within the same Warburgian concepts a methodology that helps to work within the new scope of comparative literature. The terms Nachleben, Denkraum, and Umfangsbestimmung will shape this proposal.
\end{abstract}

\section{Keywords}

Warburg, Nachleben, Denkraum, Umfangsbestimmung, comparative literature

\footnotetext{
$66 \mathrm{H}$

mundo (o al menos el nuestro) ha estado en crisis permanente al menos desde 1914” es la frase con la que René Wellek (1959) comienza su popular artículo en el que aboga por una revisión de los objetivos y métodos de la literatura compa-
} 
rada. Quizá podríamos incluso agregarle un siglo más a ese "estado de permanente crisis" si tomamos en cuenta que desde 1831 Hegel había puesto en la mesa de debate (quizá sin saberlo) la muerte del arte (Vorlesungen über die Ästhetik), y más tarde Nietzsche, siguiendo sus pasos, afirmó en 1882 que Dios también había muerto (Die fröhliche Wissenschaft). Y, sin embargo, aquí estamos en 2020 preguntándonos si existe algo parecido a una literatura comparada.

La comparación existe sin duda, es la acción de examinar atentamente (una cosa o a una persona) para establecer las semejanzas o diferencias con otra (Real Academia Española, 2005); también existe como figura retórica y "resulta ser un elemento casi imprescindible para la descripción” (Beristáin, 2006: 96-97); o sea, siguiendo a Beristáin, es parte indispensable del lenguaje. Comparar es una de las actividades más frecuentes y comunes que realiza el ser humano; como método existe desde el siglo XVII en la investigación científica; como actividad humana, desde siempre. Para el filósofo presocrático Anaxágoras, al principio todas las cosas estaban juntas en una misma. Como lo retoma más tarde Platón, el acto de comparar y discernir todo ese caos es lo que da forma al universo, lo que le da sentido a la vida y a la muerte (Platón, 1903: Fedón 72c). El juego entre los verbos griegos

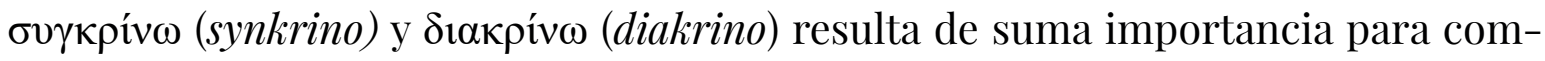

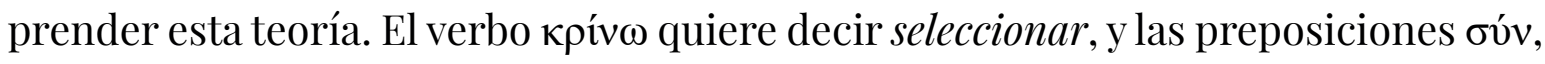
con, y dió, a través, señalan dos actividades esenciales para la naturaleza, y también para toda tarea de investigación, que podríamos traducir por comparar y discernir.

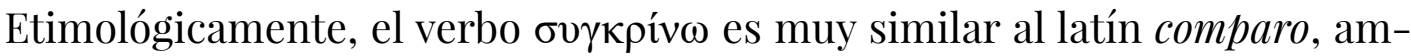
bos formados con la misma preposición en español. Para Cicerón (1913), el orador romano, la comparación era una de las cualidades que separaban al hombre de las bestias (1.4.11). Para Quintiliano (1920), el autor del manual de oratoria, la comparación formaba parte de los tropos más comunes del lenguaje: la metáfora. Una metáfora breve es una similitud, y una similitud consiste en "comparar las cosas, que se quieren expresar; se dice algo de este mismo a través de otra cosa” (Quintiliano, 1920: VIII.6). La comparación es parte de la vida diaria; afirma Quintiliano (1920) al inicio de su retórica que todo orador debe tenerla presente, pues "ciertamente no es necesario que nada se otorgue, a quien con nadie se compara” (I.1). 
La comparación es una parte imprescindible del lenguaje; sin ella sería imposible imaginar cosas que no conocemos y que sólo pueden tomar forma a partir de aquello que nos resulta cotidiano. La comparación nos permite explorar mundos nuevos. De ahí que el estudio de la literatura en general dependa en gran medida de ella, y también de ahí que no podamos restringir su estudio a las letras. La comparación forma parte de la manera en que entendemos al mundo entero. Por lo tanto, George Steiner (1997) no se equivoca al afirmar que la literatura comparada es "todo acto de recepción de forma significativa en las lenguas, el arte y la música” (171).

Hoy en día la literatura comparada se acerca más a los estudios culturales comparados "ya que el estudio de la cultura y de los productos culturales -que incluyen, sin restringirse a la literatura, comunicación, medios, arte, etcéterase realiza en un constructo contextual y relacional, y con pluralidad de métodos y acercamientos, interdisciplinarios, y, si es requerido, incluyendo el trabajo en equipo" (Tötösy, 1999: 14). Por lo tanto, esta nueva disciplina requiere de una metodología que apele al multiculturalismo y la interdisciplinariedad a fin de sentar las bases para una literatura comparada del futuro.

Los estudios culturales forman parte de disciplinas de reciente creación a partir de los cambios que le trajo el siglo XIX a la filosofía, las artes y la literatura. Uno de los cambios de mayor relevancia fue la reforma humboldtiana de las universidades alemanas, misma que llevó a la creación de la Universidad de Berlín (1810), pero cuya influencia no se circunscribió a ella. La reforma humboldtiana fue un movimiento con repercusiones en un amplio rango de instituciones europeas que se desarrolló durante un largo periodo de tiempo y como respuesta a numerosas causas como la Revolución Francesa, las Guerras Napoleónicas y las guerras Franco-Prusianas. El concepto de Bildung fue el núcleo de este movimiento en las nuevas universidades y cuya traducción nos llevaría a examinar conceptos como la paideia griega y el papel que jugaba la polis en la educación de la Grecia clásica (véase Horlacher, 2014). Esta reforma no sólo defendió la importancia de la investigación en las universidades, sino también de la docencia y del intercambio dialéctico entre estudiantes y maestros (Östling, 2018: 38), así como la libertad de cátedra y el acercamiento entre academias que permitiera el intercambio interdisciplinar. 
Este hecho trajo consigo un renovado interés en los clásicos grecolatinos reforzado por la influencia de autores como Joachim Winckelmann (Gedanken über die Nachahmung der griechischen Werke in der Malerei und Bildhauerkunst, 1755), que dio origen a un movimiento en la literatura, la educación y la política conocido como neohumanismo (Gossman, 1994: 3). Autores como Goethe, Schiller, Hölderlin y Hegel recibieron y alimentaron este espíritu. Para ellos, la Grecia clásica era la cuna de toda armonía y belleza, por lo tanto, el ejemplo a seguir y la medida de comparación de todas las cosas. Los primeros trabajos de la disciplina se dieron en la comparación de los clásicos y otras literaturas. Los turbios inicios de la literatura comparada se encuentran con conceptos como "folklor", "literaturas del mundo" o "nacionalismo", hoy caídas en desuso, e incluso rechazadas por nuevas miradas multiculturales e inclusivas (Wellek y Warren, 1949: 41).

La literatura comparada surgió entonces a partir de este nuevo panorama. La primera vez que apareció este término en inglés fue cuando en 1848 Matthew Arnold tradujo el francés "histoire comparative" en la obra Jean-Jacques Ampére por "comparative literature" (Wellek y Warren, 1949: 38). ${ }^{1}$ La obra de Ampére, como De la littérature française dans ses rapports avec les littératures étrangères au Moyen Âge (1833) o Histoire littéraire de la France avant le xIIe siècle (1839), consistía en efecto en lo que se estableció en aquel momento como la línea de los estudios en la disciplina. En francés el término "litterature comparée" había comenzado a ser utilizado alrededor de 1820 en el marco de la cátedra sobre elocuencia que François Villemain impartía en la Sorbona, misma que resultaría en la publicación de los tomos Tábleau de la littérature au XVIII siècle y Tảbleau de la littérature au Moyen Age en France, en Italie, en Espagne et en Anglaterre, dirigidos a "los aficionados a la literatura comparada” entre 1828 y 1830 (D’haen, 2012: 51). Wellek y Warren (1949) afirman que esta orientación se vio influenciada por los estudios científicos como la anatomía y paleontología, y mencionan la anatomía comparada de François Cuvier -Le Règne animal distribué d'après son organisation, 1817- (38).

${ }^{1}$ Arnold, el traductor, fue en efecto un gran defensor de los estudios comparados. Para él, "ninguna literatura podía ser adecuadamente comprendida aislada de otros eventos, otras literaturas" (Rapple, 1989: 36). 
Regresando a Alemania, los inicios de la literatura comparada nos llevan a recordar a los miembros del Sturm und Drang, como a August Wilhelm von Schlegel y su cátedra sobre literaturas del mundo en Berlín entre 1802 y 1804, así como su conferencia sobre arte dramático y literatura en Viena en 1808. También a su hermano menor, Friedrich Schlegel, y su Geschichte der alten und neueren Literatur de 1815 (Jantz, 1936: 402). Resulta curioso que los estudios de literatura comparada que buscan tejer este tipo de genealogías de la disciplina suelen recurrir a estos nombres y, sin embargo, dejan de lado los trabajos que se acomodan mejor a ella desde las metodologías contemporáneas, siempre ávidas de la interdisciplina e intermedialidad. Considero que dentro de un panorama más amplio no deberíamos dejar de lado el trabajo de Gotthold Ephraim Lessing, Laokoön oder Über die Grenzen der Malerei und Poesie que, en 1767, se erigió como pionero de la comparatística al analizar los límites entre la poesía y la pintura, aunque tradicionalmente se trata de un trabajo citado en el campo de la filosofía y la estética. Además, esta obra fue de suma importancia en la formación de Aby Warburg (Gombrich, 1970: 23), de quien trata este artículo, quien estudió Historia del Arte en la Universidad de Bonn fundada en 1818, en el marco de la reforma humboldtiana. Ahora bien, ¿cuál era el panorama de los estudios en la Historia del Arte en este mismo momento?

Warburg estudió con Karl Lamprecht (Die kulturhistorische Methode, 1900), para quien "El arte, entonces, es el indicador supremo del maquillaje psicológico de un periodo dado y la comprensión de los principios que lo rigen deben guiarnos directamente al centro y corazón de la época” (Gombrich, 1970: 33; cf. Báez, 2012: 12). Esta visión se encontraba impregnada del concepto de historia de Hegel (Phänomenologie des Geistes, 1807), por una parte, y, por otra, de Jacob Burckhardt (Die Cultur der Renaissance in Italien, 1860), figura dominante en los estudios de historia cultural (Kulturgeschichte). Otra parte importante de su formación estuvo a manos de Carl Justi (Gombrich, 1970: 27), quien, con una visión diferente a Lamprecht, enseñó a Warburg la historia del arte como “descripción, narración, contextualización (dentro de la época, dentro de la disciplina), búsqueda de fuentes y documentos" (Lescourret, 2013: 87). 
En este marco de pensamiento aparece Aby Warburg, cuya tesis doctoral sobre el trabajo de Boticelli parte justamente de la comparación entre la literatura clásica y la del Renacimiento Italiano, así como de su influencia en el arte. Ante este panorama de los estudios es fácil comprender a Warburg como un historiador del arte sintomático, como define Georges Didi-Huberman (2002) "a este complejo movimiento serpentuoso, esta intrincación no resolutiva, esta no-síntesis" (274).

Los estudios de Warburg se encuentran entre los primeros acercamientos comparatistas, multiculturales y diacrónicos. Afortunadamente, en fechas recientes, el nombre de Aby Warburg y su trabajo han pasado por un refrescante renacimiento. La bibliografía que se ha publicado sobre este autor suma en nuestros días un aproximado de 3500 tomos entre los que se cuentan estudios de literatura, filología y otras disciplinas (Lescourret, 2013). ${ }^{2}$ Investigaciones como las pertenecientes al área de Historia del Arte han hecho amplio uso del trabajo que nos heredó. La propuesta de este artículo es encontrar entre los mismos conceptos warburgianos un camino que ayude a trabajar dentro de los nuevos alcances de la literatura comparada. Los términos Nachleben, Denkraum y Umfangsbestimmung ayudarán a formar esta propuesta.

\section{Aby Warburg}

Hablar de Aby Warburg y su método implica afrontar diferentes retos. En primer lugar, se debe mencionar la imposibilidad de abarcar el amplio rango que ocupan sus escritos y los estudios derivados de ellos. Esto se debe a la riqueza teórica de su trabajo que podemos encontrar en diferentes aspectos. Uno de ellos es el interés interdisciplinar de su autor, mismo que lo vuelve adecuado para los fines de esta investigación. En segundo lugar, las características de su lenguaje que, como lo define Linda Báez (2012), "se orienta a articular y condensar dos aspectos: el metafórico y el científico" (14), y da como resultado aforismos que imitan fórmulas científicas y neologismos con tintes metafóricos, como lo son Nachleben, Denkraum y Umfangsbestimmung.

${ }^{2}$ Véase https://aby-warburg.blogspot.com/2009/12/aby-m-warburg-bibliografie-2006-bis. html de Björn Biester. 
Aby Warburg fundó un instituto, creó una biblioteca única en el mundo, coleccionó y catalogó miles de imágenes y nos legó una serie de artículos, ensayos y conferencias junto con una serie de notas en tarjetas dentro de unos hermosos ficheros de papel. En total se suele afirmar que creó una nueva disciplina, una ciencia sin nombre. Él mismo a veces se refería a ella como una "psicología histórica de la expresión humana" (Warburg, 2005: 415) o una "historia de la cultura" (Warburg, 2004: 10) y, a veces, simplemente como "nuestra joven disciplina" (Warburg, 2005: 434). Robert Klein (1970) describió esta ciencia como "una que, al contrario que tantas otras, que existe, pero no tiene nombre" (224), comentario que Giorgio Agamben (2008) retomó para titular su ensayo dedicado al trabajo de Warburg. La indeterminación de estos estudios ha funcionado a su favor, ya que hoy en día los investigadores que se han abocado a perpetuar la disciplina de Warburg no se ven limitados por estereotipos académicos o científicos. Continuadores de este trabajo son Ernst Cassirer, Fritz Saxl, Gertrude Bing y algunos otros autores célebres como Ernst Gombrich, Erwin Panofsky y Frances Yates. En años recientes, el interés que han mostrado por Warburg investigadores como Georges Didi-Huberman, quien publicó su libro La Imagen Superviviente en 2002 y, más tarde, curó una exposición en el 2010 en el Museo Reina Sofía titulada Atlas, llevar el mundo a cuestas, acompañada de una serie de lecturas en París y Madrid, han permitido un resurgimiento de publicaciones y estudios dedicados al trabajo y la personalidad de Aby Warburg. Esta avalancha de textos suscitada en los últimos años y que incluye trabajos en castellano, francés, alemán e italiano pone de manifiesto un innegable renacer de esta ciencia innombrable.

Entre estas publicaciones se cuentan la traducción, edición y re-edición de algunos de los trabajos de Warburg que, aunque fragmentarios y diversos, comprenden la piedra fundacional de esta famosa ciencia también conocida como Kulturwissenschaft o ciencia de la cultura. Los primeros atisbos de sus alcances y las trazas de sus orígenes pueden ser aprehendidos en las más tempranas investigaciones de Aby Warburg, como es el caso de su célebre tesis sobre la El Nacimiento de Venus y la Primavera de Botticelli. Este artículo fue presentado en 1891 como el producto de sus estudios doctorales. 


\section{Nachleben}

El problema que aquejaba a Warburg, en una disciplina como la Historia del Arte a finales del siglo XIX, era el común acercamiento desde la teoría de los estilos que parecía encuadrar (por no decir empobrecer) las investigaciones. Para Warburg, de cierta manera, la verdadera interrogante se hallaba en la razón por la cual los lienzos de Sandro Botticelli eran considerados, y siguen siendo, la máxima expresión de ese movimiento humano conocido como Renacimiento (véase Figura 1). Después de leer la tesis, la respuesta parece sencilla: los accesorios en movimiento (Bewegtes Beiwerk), o sea, el cabello de la diosa romana revuelto a merced del Céfiro junto con las telas de su ropaje. Posteriormente, el mismo Warburg (2005) resumió los objetivos de este trabajo como la constatación de que "la influencia de la Antigüedad en la pintura profana del Quatroccento [...] se manifestó en la estilización de los modelos humanos a través de la acentuación del movimiento del cuerpo y los ropajes, siguiendo tipos que se encontraban en las artes plásticas y en la poesía antigua” (415). Así, mostró los senderos por medio de los cuales la Antigüedad pagana sobrevivía en la cultura del siglo XVI.

Figura 1

El nacimiento de Venus (1485-1486)

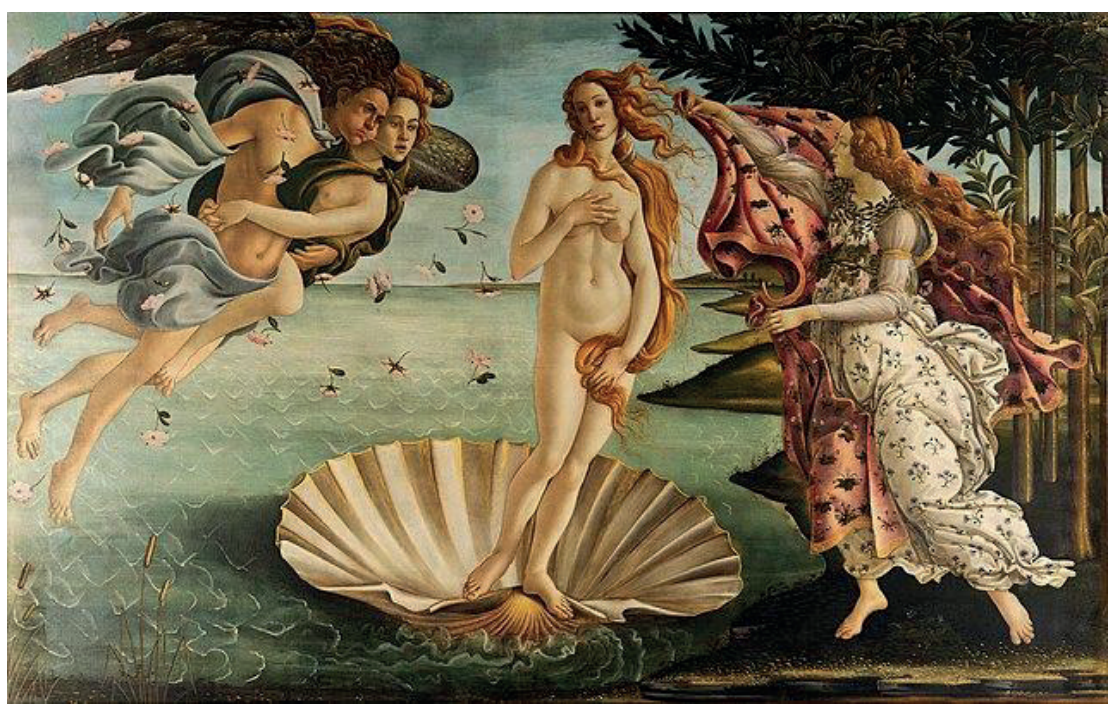

Nota: Autor: Sandro Botticelli. Témpera sobre lienzo Original en Galería Uffizi, Florencia, Italia. Recuperado de «https://commons.wikimedia.org/wiki/ File:El nacimiento de Venus, por Sandro Botticelli.jpg» Dominio público. 
La verdadera tesis consistió en unir esta interpretación gráfica con los versos de Ovidio y Claudiano en los que se describe a detalle el movimiento de estos accesorios. Encontró las referencias exactas en los versos de las estancias del Palacio de Venus de La Giostra del poeta florentino Poliziano, donde se describe el Rapto de Europa. En su trabajo, además de citar fielmente los versos tanto toscanos como latinos, Warburg recorta y acomoda los versos que le interesan de esta manera:

E lei volgere il viso al lito perso

Met. II, 873: ...litusque ablata relictum respicit

In atto paventosa: e i be'crin d'auro

Met. II, 873: pavet haec. Fasti V, 609: flavos movet aura capillos

Scherzon nel petto per lo vento avverso

Met. I, 528: obviaque adversas vibrabant flamina vestes

et levis inpulsos retro dabat aura capillos

La vesta ondeggia, e in drieto fa ritorno

Met. II, 875: tremulae sinuantur flamine vestes

Fast. V, 609: Aura sinus inplet

L'una man tien al dorso, el'altra al corno

Met. II, 874: ... dextra cornum tenet, altera dorso imposita est

Est. 106: Le ignude piante a sè ristrette accoglie

Fast. V, 611: Saepe puellares subduxit ab acquore plantas

Quasi temendo il mar che lei no bagne

Ibíd. V, 612: et metuit tactus assilientis aquae ${ }^{3}$

${ }^{3}$ Copio los versos de la edición de Warburg (2004). Corresponden a la edición del poema escrito en 1475 de G. Carducci, Le Stanze, l'Orfeo e le Rime di M. A. A. Poliziano, publicada en Florencia en 1863, misma que utilizó Warburg para su trabajo. 
Al estilo de un collage, dispone ante los ojos de sus lectores los textos que considera dignos de resaltar. El primer verso de cada par corresponde a una estrofa del texto de Poliziano redactado en 1475, mientras que el segundo renglón, resaltado en cursivas y señalado con sus abreviaturas, combina versos de las Metamorfosis y los Fastos de Ovidio del primer siglo de nuestra era, con el fin de dejar clara la influencia que tuvo el poeta latino en el escritor del Renacimiento. La inspiración ovidiana en algunos casos es casi textual, como sucede entre el be'crin d'auro y los aura capillos de las Metamorfosis en el segundo verso. En otras ocasiones es perifrástica, como sucede en el cuarto verso donde el verbo latino sinuantur fue traducido por in dietro fa ritorno. La labor de subrayar esta unión poética entre Poliziano y los poetas latinos representó sin duda una gran aportación a los estudios culturales y la temprana literatura comparada.

Como se puede notar, Angelo Poliziano (La Giostra, 1475) fue un lector atento de los poetas latinos y consiguió contagiar a su amigo Sandro Botticelli del entusiasmo por estas vívidas descripciones, que aparecen plasmadas en el lienzo, como evidencia Warburg en su trabajo. Las fuentes clásicas de esta inspiración no se limitan a un ejemplo, sino que se suman también a Claudiano con el Rapto de Proserpina (395-397) y se remontan en el tiempo hasta el Himno Homérico a Afrodita. ${ }^{4}$ A este análisis literario se suman los testimonios de los contemporáneos de Poliziano, como los arquitectos Roberto Valturio (De Re militari, 1472) y Filarete (Trattato di architettura, 1461-1462), y el historiador del arte Giorgio Vasari (Las vidas, 1550). Asimismo, esta teoría se ve reforzada con ayuda de algunos escritos teóricos, como el Tratado de la pintura (1450) de León Battista Alberti, quien aconsejaba imitar el movimiento del viento en los cabellos de las doncellas para hacerlos parecer más naturales en la pintura: "Los movimientos de los cabellos, las crines, las ramas, las hojas y las vestimentas deleitan expresados en una pintura. Me gusta que los cabellos se muevan en los que llamé los siete modos...” (citado en Warburg, 2005: 78).

${ }^{4}$ Los himnos homéricos son un conjunto de 33 textos, escritos entre el siglo VII a. C. y hasta la época helenística. Su autor es desconocido; se llaman homéricos porque están escritos en el mismo verso que la Ilíada y la Odisea (hexámetros dactílicos), aunque no tienen nada que ver con Homero. Fueron fuente de inspiración para muchos poetas. 
Este análisis está complementado por imágenes que ayudan a evidenciar la tesis acerca de los accesorios en movimiento. Entre estos ejemplos se encuentran testimonios contemporáneos como la obra de Agostino di Duccio (véase Figura 2) y un grabado de la Hypnerotomachia Poliphili (1499) (véase Figura 3), entre otros, confrontados a fuentes más antiguas como los relieves de algunos sarcófagos romanos (véase Figura 4) (Warburg, 2005: 86). De estas representaciones, Warburg resalta cómo "Las figuras basadas sobre modelos antiguos nos enseñan cómo un artista del siglo XV escogía de una obra antigua sólo aquello que le “interesaba” (Warburg, 2005: 84). Un ejemplo emblemático de esta irrupción de la antigüedad en la figura de la Ninfa durante el temprano Renacimiento se encuentra en el fresco del Nacimiento de Fuan Bautista de Ghirlandaio (Figura 5).

Figura 2

Ángel con aulós (1450 ca.)

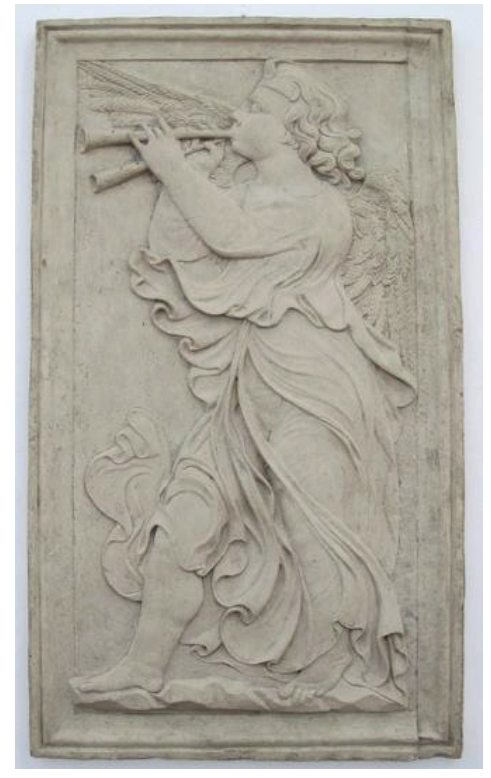

Nota: Autor: Agostino di Duccio. Tallado sobre piedra. Original en Templo Malatestiano, Rímini, Italia. Recuperado de «https://commons.m.wikimedia.org/wiki/File:Calco ai angelo musicante di agostino di duccio da tempio malatestiano.JPG». Copyright de la imagen 2013, por Sailko. Compartida con una licencia Creative Commons CC BY-SA 3.o. 


\section{Figura 3}

Florido Veri (1499)

Nota: Autor: Anónimo. Xilografía. Original en Hypnerotomachia Poliphili, Biblioteca Beinecke de Manuscritos y Libros Raros, Connecticut, Estados Unidos. Recuperada de «https://commons.wikimedia.org/wiki/File:Hypnerotomachia Poliphili pagi192.jpg» Dominio público.

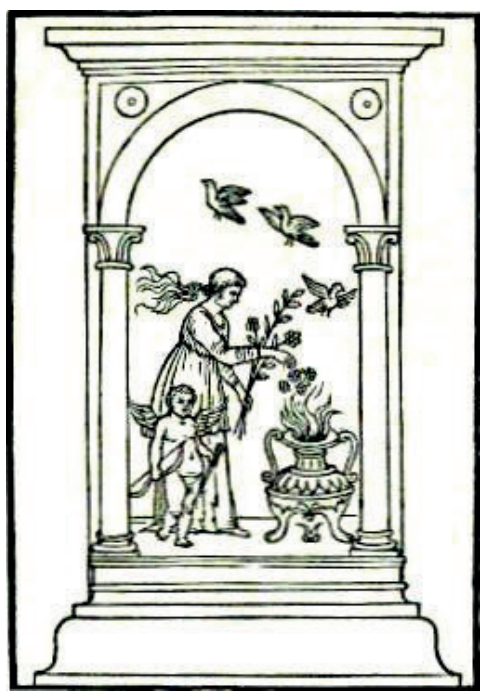

\section{Figura 4}

Procesión báquica (ca. I d. C.)

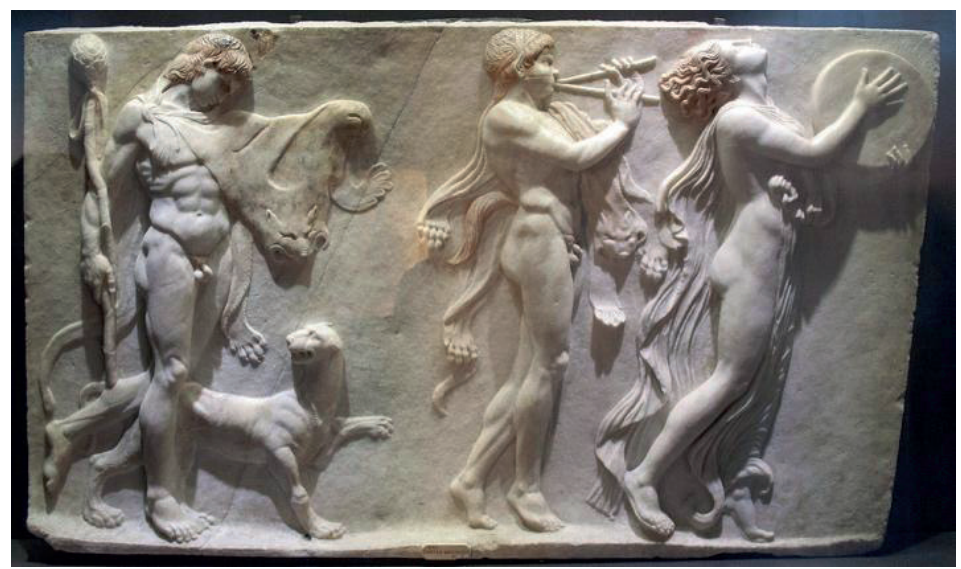

Nota: Autor: Anónimo. Relieve en mármol. Original en Museo Británico, Londres, Inglaterra. Imagen recuperada de «https://commons.wikimedia.org/wiki/File:Bacchic procession, Colosseum.jpg». Dominio público. 


\section{Figura 5}

\section{El nacimiento de San Fuan Bautista (1486-90)}

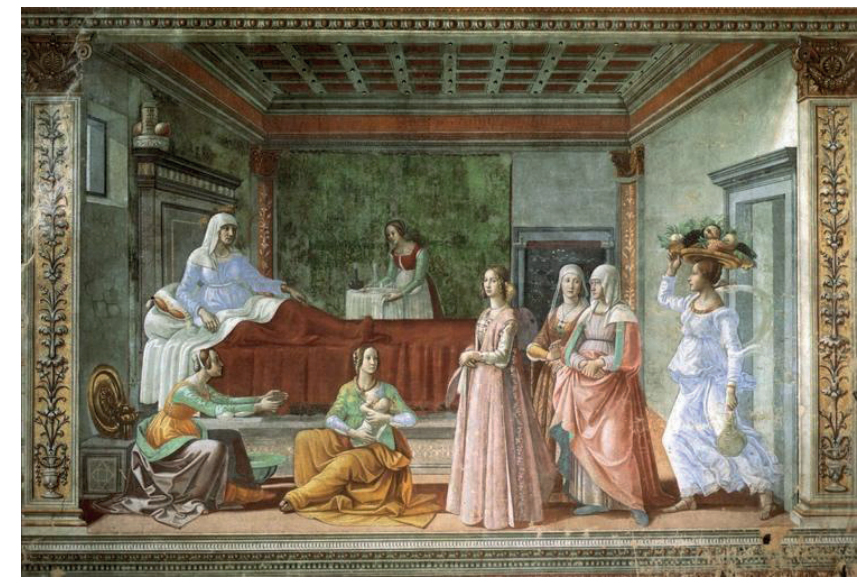

Nota: Autor: Domenico Ghirlandaio. Fresco. Original en Capilla Tornabuoni, Florencia, Italia. Imagen recuperada de «https://commons.wikimedia.org/wiki/File:Birth of St John the Baptist.jpgo» Dominio público.

La importancia de la tesis de Botticelli radica en la selección de los ejemplos y sus fragmentos, tanto los textos como las imágenes vistos en conjunto, que se despliegan ante los ojos del estudioso dejando en evidencia su relación irrefutable. Aquí se consiguen avistar los alcances del último gran trabajo que emprendió Warburg en su vida, el Atlas Mnemosyne, un mecanismo cuyo último fin pudiera haber sido posibilitar la contemplación de las imágenes como si se tratara de textos, descompuestos en verbos, adjetivos y sustantivos entrecruzados en diferentes ejemplos poéticos, sin importar la fecha de su elaboración, para mostrar sus correspondencias. La importancia del mecanismo Atlas, en palabras de Christopher Johnson (2012), consiste en su objetivo de "mapear tanto las fuerzas subjetivas como las objetivas que han moldeado a la cultura occidental [...] lo que sólo aumenta su aplicación para las formas del pensamiento comparatista del siglo XX, que también tiende, para bien o para mal, a considerar la subjetividad crítica como un elemento combinatorio en la tarea de la interpretación” (11). La elaboración de constelaciones creadas a través de los lienzos negros con imágenes, acompañados de textos 
permitirían crear una historia visual de la cultura occidental. "El Atlas presentaría así una visión cosmográfica, es decir, un sistema de relaciones entre mapas que abarcasen tanto la dimensión espacial como temporal y requirieran de la grafía (texto) para su correcta inscripción” (Báez, 2012: 40).

Aunque de este trabajo, inacabado a la muerte de Warburg, sólo conserva-

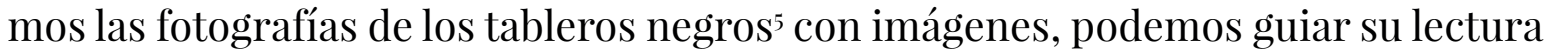
gracias a los artículos, apuntes y notas, y por supuesto, el acervo de su biblioteca. En él también queda manifiesta la profunda voluntad comparatística de nuestro autor al enfrentar imágenes lejanas en tiempo y espacio, en espera de que su buena vecindad devele similitudes, diferencias y supervivencias. Por ejemplo, en su trabajo sobre El mundo de los dioses antiguos y el primer Renacimiento en el norte y el sur, de 1908, decidió mostrar cómo las divinidades antiguas habían sobrevivido en la forma de los dioses planetarios como Saturno y Venus. Logró esto a través de dos medios: "En primer lugar, con las descripciones de dioses de la Antigüedad tardía que se conservaron durante la Edad Media bajo el ropaje solemne de la alegoría moral, fundamentalmente en la introducción a la interpretación alegórica de Ovidio. En segundo lugar, [mostrando cómo] la astrología constituye una tradición iconográfica ininterrumpida" (Warburg, 2005: 409). Así, el Atlas Mnemosyne ayuda a comprender el tipo de memoria que supone el Nachleben: "que transforma toda nuestra idea de la tradición: esta no es ya un río continuo en el que las cosas se transmiten simplemente de cabecera a desembocadura, sino una dialéctica tensa, un drama que se representa entre el curso del río y sus propios remolinos" (citado en Didi-Huberman, 2002: 93). ${ }^{6}$ Finalmente, como afirma Christopher D. Johnson

${ }^{5}$ Se trataba de 63 bastidores de madera que medían más o menos 150 y $200 \mathrm{~cm}$ cubiertos de tela negra. De éstos sólo conservamos las fotografías de la "última versión" o como se encontraban al momento de la muerte de Warburg, mismas que fueron publicadas en el año 2000 en Gesammelte Schriften, edición de Martin Warnke. Cabe recordar que se trata de una versión petrificada, inmóvil, de lo que en la vida de Warburg fungió como un mecanismo vivo y en constante cambio dependiendo de los temas, autores que estaba estudiando, e incluso de las condiciones de acceso a las imágenes que, en la época, en muchos casos involucraban viajes o comisiones internacionales. "En cada uno de estos páneles (Táfeln) Warburg, usando pinzas de metal, agregaba y quitaba, acomodaba y reacomodaba, reproducciones fotográficas a blanco y negro de imágenes de historia del arte o cosmográficas" (Johnson, 2012: 9). (Todas las traducciones de este texto son de la autora.)

${ }^{6}$ Traducción de Juan Calatrava en la edición de 2009, p. 82-83. Cf. Bing (1965: 301-302 y 310). 
(2012), "Yuxtaponer objetos separados por una amplia distancia cronológica es la manera más obvia de probar la Nachleben der Antiken, la supervivencia de lo antiguo" (75), lo cual consiste en la metodología del Atlas y la tesis de Boticelli.

\section{Denkraum}

Cuando en 1920 un joven Ernst Cassirer fue a visitar la colección en Hamburgo, declaró: "Esta biblioteca es peligrosa. Tendré que evitarla por completo o podría quedarme aquí preso durante años" (Settis, 2010: 30). La justificación a este miedo resulta comprensible, ya que el edificio no sólo guardaba los libros que Warburg consideró que debería estudiar para resolver el problema que lo ocupó a lo largo de toda su vida - la supervivencia de la Antigüedad clásica y su influencia en la formación del pensamiento moderno europeo (Checa, 2010: 9) -: también proponía un recorrido único para el que podríamos utilizar el neologismo que él mismo acuñaría: Denkraum, espacio de pensamiento. Los alcances de esta colección bibliográfica no eran personales; pronto, Aby cayó en cuenta de que gracias al apoyo familiar podría obtener muchos textos invaluables para su tarea académica, pero que, por otra parte, leerlos todos representaba una tarea imposible de lograr. Fue gracias a su profunda vocación didáctica (Pasquali, 2014) que decidió coleccionar y acomodar los libros de manera que ayudaran a otros estudiosos, sus futuros alumnos, a continuar con su trabajo. Esta disposición no responde al acomodo convencional de las grandes bibliotecas a lo largo del mundo, sino a la ley del "Buen Vecino", como a él le gustaba llamarla. La distribución de los libros no depende de un código alfanumérico, sino de su título y su contenido. Esto quiere decir que divisiones tradicionales entre disciplinas no figuran en ella. Warburg acomodaba y reacomodaba los libros con el fin de localizar los que ayudarían a resolver un mismo problema unos juntos a otros; de esta manera también se aseguraba de que esta búsqueda generara nuevas interrogantes, redireccionando los paseos de los lectores por los anaqueles y las investigaciones de los mismos.

La formación de esta biblioteca se dio, por una parte, de manera natural al paso que nuestro estudioso continuaba y ampliaba sus investigaciones; por otra, 
fue posible gracias al compromiso que la familia Warburg asumió en el desarrollo de la cultura en un ambiente internacional en el que los antecedentes de las Guerras Mundiales no pasaban desapercibidos. El nivel de involucramiento de los Warburg en esta tarea los llevó incluso a construir un edificio para alojar la biblioteca que facilitó el surgimiento de un instituto capaz de alojar una nueva ciencia de los estudios culturales. La construcción ubicada en Hamburgo goza de una bella sala oval al centro que distribuye a su alrededor los anaqueles con libros agrupados en cuatro conjuntos atípicos. Los nombres para cada una de las secciones son Imagen, Palabra, Orientación y Acción (Settis, 2010: 82). El primer grupo está conformado por títulos referentes a la Historia del Arte. La segunda, la Palabra, es la que llama nuestra atención como filólogos, ya que colecciona la literatura griega y romana acompañadas de filosofía, historia y mitología. El tercer nivel, la Orientación, corresponde a la religión, ciencia y filosofía, y finalmente el cuarto, la Acción, a la historia política y social. Esta clasificación simplifica a muy grandes rasgos la colección bibliográfica que en ocasiones se detiene en particularidades como, por ejemplo, la Orientación que incluye a la magia, la alquimia y la adivinación como estado de transición entre el mito y la ciencia (Hagelstein, 2008: 16).

El sustantivo Denkraum, formado por Denken - pensamiento o reflexión-y Raum - espacio - aparece por primera vez en los escritos de Warburg en la conferencia que presentó en 1918 frente a la Asociación de Ciencias de la Religión de Berlín, titulado "Profecía pagana en palabras e imágenes en la Época de Lutero" y que publicó en 1920:

Nos encontramos en el tiempo de Fausto, en que el científico moderno intentaba - entre la práctica mágica y la matemática cosmológica- conquistar un espacio de pensamiento (Denkraum) reflexivo entre él y los objetos. Parece que, efectivamente, Atenas debía ser reconquistada una vez más desde Alejandría. (Warburg, 2005: 490)

Este término en general servirá para hacer referencia al espacio en el que el artista concebía la obra de arte y también el espacio en que el crítico elaboraba su discur- 
so. Aunque se encontrarán otros significados que muchas veces dependerán del contexto y de las combinaciones léxicas que Warburg hacía como "Bewusstsein vom Denkraum", "la conciencia de pensar en el espacio"; "Cheirokratie und Denkraum", "el gobierno de la mano y el espacio de pensamiento"; "Denkraum in statu nascendi"; "Denkraumschöpfung als Kulturfunktion", "la creación del espacio mental como una función cultural"; "Denkraumverlust", "la pérdida del espacio mental”; "mathematischer und psychotechnischer Denkraum", "matemática y psicotécnica del espacio mental”, entre otros (véase Treml, Flach y Schneider, 2014: 11).

Así también la disposición de la biblioteca se convierte en el Denkraum físico de Warburg (Hagelstein, 20o8: 14). En ella se puede vislumbrar algo parecido a un método, pues como Salvatore Settis (2010) apunta, el acomodo de la biblioteca es también un "itinerario mental que reconstruye no ya la historia de Aby Warburg, sino la forma que tomó su trabajo cotidiano de los últimos años” (28). Esta disposición

debe guiar desde la imagen visual (Bild) como primer estadio en la conciencia del hombre, al lenguaje (Wort) y de ahí a la religión, la ciencia y la filosofía, todas ellas productos de la búsqueda del hombre de Orientación (Orientierung) que influenciara sus patrones de comportamiento y sus acciones, el contenido de la historia. La acción, la representación de ritos (Dromena) es a su vez suplantada por la reflexión, que restituye la formulación lingüística y la cristalización de imágenes que completan el ciclo. (Settis, 2010: 65)

Este recorrido metodológico tiene la ventaja de motivar, a través de los materiales de trabajo, al investigador a indagar desde diferentes puntos de vista un mismo problema cuyo objetivo es encontrar el significado de la Antigüedad en las formas de arte posteriores, particularmente el Renacimiento italiano, a través de una memoria viva. 


\section{Umfangsbestimmung}

Este término nos permite subrayar la vocación comparatista de Warburg. En sus escritos aparece frecuentemente la palabra comparación (Vergleich), de manera particular en las fichas que elaboró desde 1888 hasta 1905 y que han sido agrupadas bajo el título Fragmentos sobre la expresión, publicadas en varias ediciones. De acuerdo con Susane Müller, quien dirige la versión francesa de los Fragmentos - misma que utilicé para este estudio-, "[e]stos fragmentos a través del lenguaje, y a semejanza de su maestro, parten de singularidades para llegar al todo. Buscan establecer leyes generales a partir de fenómenos" (en Warburg, 2015: 12). En la lectura de estas notas resulta claro que para Warburg la comparación era parte fundamental de la creación tanto artística como científica y se encuentran algunos intentos por definir las características de este proceso:

Toda comparación (Vergleich) está precedida de un distanciamiento del perímetro (Umfang) real en el que se encuentra el portador (Träger), a favor de la atención de referir al portador hasta que este sea sustituido por otro soporte que siga el mismo objetivo con mayor homogeneidad (de la voluntad o del cuerpo). (Warburg, 2015: 130) ${ }^{7}$

De esta cita cabe recuperar dos términos: en primer lugar, el de portador (Träger), que Warburg define de esta manera: "En una imagen, el objeto no es solamente considerado por aquello que le vuelve esencial en un momento preciso en el seno de una serie de objetos, dicho de otra manera, por eso que lo distingue, sino en tanto que es portador (Träger) vivo de una serie de cualidades que comparte simultáneamente con un gran número de objetos" (Warburg, 2015: 74). ${ }^{8}$ El objeto de la imagen soporta una serie de cualidades que comparte con un gran número de objetos y por ello es susceptible de comparación; de ahí que pueda ser considerado un portador (Träger). Por otra parte, la existencia de la imagen está determinada

${ }^{7}$ Nota 181 , con fecha del 14 de mayo de 1891

${ }^{8}$ Nota 55 , fechada el 15 de marzo de 1890 
por las características del perímetro en el que nace. El término Umfang, perímetro, también aparecerá frecuentemente en las notas de Warburg, como necesario para mediar entre el sujeto y el infinito (Johnson, 2012: 32). Linda Báez (2012) ha centrado sus estudios alrededor de la importancia de este concepto en unión con el verbo be-stimmen, que quiere decir condición o propósito final, relacionado a la determinatio latina cuyo origen subraya la existencia de un contorno o límite (26). El verbo alemán también está formado por el sustantivo stimmung, que significa humor, ambiente o atmósfera, como el tóvos (tonos), griego que hace referencia a cualquier objeto que se pueda estirar, incluidos los tendones del cuerpo humano, las amarras de un barco y las cuerdas de un instrumento, pero también el esfuerzo físico o mental. De esta unión de conceptos podemos entender que los límites de un espacio, real o metafórico, pueden expandirse o disminuir. La comparación es uno de los medios a través de los cuales esto es posible.

Para Warburg, la imagen es en primer lugar simbólica. Este nivel de abstracción permite imaginar varios objetos a la vez dentro de una determinación primaria que es el Umfangsbestimmung, la determinación del perímetro o poética de la circunscripción, ya que podemos considerar éste como el espacio de la creación artística (Báez, 2012: 26-27). O "eso que se coloca, desde el punto de vista corpóreo-simbólico, en el espacio: a través del lenguaje, del arte, del ser simbólico, de la capacidad de aferrarse a su objeto o también a través de la vestimenta o los instrumentos" (Tavani, 2018: 86). Un ejemplo de esto sería la formación de constelaciones: "La figura de la serpiente en el cielo [...] se usa como un perímetro matemático (mathematischen Umfangsbestimmung); los puntos luminosos se unen siguiendo una forma mundana, para volver comprensible el infinito que no podríamos comprender sin este perímetro (Umfang) de orientación” (Warburg citado en Johnson, 2012: 32). Así, para Johnson (2012) la clave de esta noción está ligada al desarrollo del pensamiento matemático, a la capacidad del hombre de diferenciar entre el infinito y el ser, común en todas las civilizaciones (33). Por lo tanto, se encuentra estrechamente ligado al concepto de símbolo que "se extiende más allá del ámbito de la recepción y conecta el campo de la percepción con el de la conciencia activa" (Zumbusch, 2004: 237). "El resultado es un Umfangsbestimmung, al 
que Warburg se adherirá hasta su trabajo en el Atlas Mnemosyne, donde finalmente coloca al arte a medio camino entre los polos opuestos de la religión y la ciencia” (Zumbusch, 2004: 245).

Por lo tanto, también engloba la importancia que encontraba Warburg en explorar la expresión a través de la dinámica de los opuestos, como el curso de un péndulo. En palabras de Georges Didi-Huberman (2009),

Toda función estará al menos “doblemente orientada” (doppeltendenziös); todo "espacio de pensamiento" (Denkraum) estará frecuentado por un "espacio de deseo" (Wunschraum) que lo guía y lo desorienta al mismo tiempo; ninguna imagen podrá ya comprenderse sin el análisis del contexto en que se inscribe y al que perturba al mismo tiempo; toda energía tenderá a expandirse, pero también a involucionarse, y también a invertirse, y así sucesivamente en un juego sin fin de metamorfosis. (429)

De esta manera el huésped del espacio expositivo warburgiano - la bibliotecaconstruye paso a paso no simplemente su camino a través del Atlas, sino su Umfangsbestimmung personal, que dibuja más una red que una trayectoria lineal (Tavani, 2018: 101). Los tres términos analizados ayudan a conformar a su vez un conjunto de criterios que servirán para comprender los elementos sobrevivientes en la literatura, las artes y la cultura a través de la comparación dentro de un espacio de pensamiento que no busque delinear un límite rígido, sino un perímetro de tensiones y juegos entre objetos y disciplinas.

\section{Conclusión}

Una disciplina en crisis es una disciplina doblemente orientada, que busca, que regresa sobre sus propios pasos, que se reinventa, que encuentra nuevos caminos y nuevos retos. Así también define Georges Didi-Huberman (1998) a Warburg, quien "nunca dejó de replantear las preguntas, lo que lo hizo re-pensar cada vez el corpus de su saber, de reorganizarlo y abrirlo a nuevos campos” (20). Considero que, así 
como han hecho otras disciplinas como la historia del arte, la literatura comparada debería encargarse de re-inventar y adaptar el corpus warburgiano a su conveniencia, pues si bien el método no se encuentra establecido (y difícilmente lo estará), propone una mirada diacrónica, multicultural e interdisciplinar como la que buscamos.

El nombre de René Wellek es frecuentemente recordado por enunciar la muerte de la disciplina. Sin embargo, quisiera recordar las conclusiones de su artículo, en las que vislumbra el futuro de la literatura comparada "en la confrontación de los objetos en su esencia: una intensa contemplación que llevara al análisis y finalmente a juicios de valor. Una vez que hayamos alcanzado la naturaleza del arte y de la poesía, su victoria sobre la mortalidad humana y el destino, su creación de un nuevo mundo de la imaginación” (Wellek, 1959: 171).

Aby Warburg se imaginó una ciencia innombrable porque no pertenecía a ninguna de las disciplinas de su época y, al mismo tiempo, necesitaba de todas. Para muchos la dificultad de este acercamiento se encuentra en la falta de un método. Mi propuesta es que sigamos la premisa de Anaxágoras: entre todo lo existente encontraremos algo con qué estudiar y a través del cual seguir investigando y así, finalmente, un orden.

\section{REFERENCIAS BIBLIOGRÁFICAS}

AGAMBEN, Giorgio. (2008). “Aby Warburg y la ciencia sin nombre”. La Potencia del Pensamiento. Madrid: Anagrama.

BÁEZ, Linda. (2012). Aby Warburg. El Atlas de imágenes Mnemosyne. Un viaje a las fuentes. Vol. II. México: IIE-UNAM.

BERISTÁIn, Helena. (2006). Diccionario de retórica y poética. México: Porrúa.

BING, Gertrude. (1965). “A. M. Warburg”. Fournal of the Warburg and Courtauld Institutes, 28, 299-313. https://doi.org/10.2307/750675

CHECA, Fernando. (2010). "Introducción”. En Salvatore Settis, Warburg Continuatus. Madrid: Ediciones de la Central. 
CiCERÓN. (1913). De Officiis (Walter Miller, ed.). Cambridge: Harvard University Press. D'HAEn, Theo. (2012). The Routledge Concise History of World Literature. Londres: Routledge.

DIDI-HUBERMAN, Georges. (1998). "L'homme qui parlair aux papillons" [Prefacio]. En Philippe-Alain Michaud, Aby Warburg et l'image en movement. París: Macula.

DIDI-HuBERMAN, Georges. (2002). L'Image Survivante, Histoire de l'Art et Temps des Fantômes selon Aby Warburg. París: Les Éditions de Minuit.

DIDI-HUBERMAN, Georges. (2009). La imagen superviviente. Historia del arte y tiempo de los fantasmas según Aby Warburg (Juan Calatrava, trad.). Madrid: Abada.

GOMBRICH, Ernst H. (1970). Aby Warburg: An Intelectual Biography. Chicago: The University of Chicago Press.

GOSSMAN, Lionel. (1994). "Philhellenism and antisemitism: Matthew Arnold and His German Models". Comparative Literature, 46(1), 1- 39. https://doi. $\underline{\operatorname{org} / 10.2307 / 1771612}$

HAGELSTEIN, Maud. (2008). “Mémoire et Denkraum. Réflexions épistémologiques sur la Kulturwissenschaftliche Bibliothek Warburg”. Conserveries Mémorielles: Revue Transdisciplinaire, (5), 38-46. http://cm.revues.org/104

HORLACHER, Rebekka. (2014). “Qué es Bildung? El eterno atractivo de un concepto difuso en la teoría de la educación alemana”. Pensamiento Educativo. Revista de Investigación Educacional Latinoamericana, 51(1), 35-45. http://dx.doi. org/10.7764/PEL.51.1.2014.16

JANTZ, Harold S. (1936). "The Fathers of Comparative Literature”, Books Abroad, 10(4), 401-403. https://doi.org/10.2307/40077574

JOHnson, Christopher. D. (2012). Memory, Metaphor and Aby Warburg's Atlas of Images. Ithaca: Cornell University Press.

KLEIN, Robert. (1970). La Forme et l'intelligible. París: Gallimard.

LESCOURRET, Marie-Anne. (2013). Aby Warburg ou la tentation du regard. París: Hazan. ÖSTLING,Johan (2018). Humboldt and the Modern German University. An Intellectual History. Lund: Lund University Press.

PASQUALI, Giorgio. (2014, marzo). "Ricordo di Aby Warburg ('Pegaso' II, 4, 1930, 484-495)". La Rivista di Engramma, (114), http://www.engramma.it/eOS/index. php?id_articolo $=1530$ 
Platón. (1903). Platonis Opera (John Burnet, ed.). Oxford: Oxford University Press. QUINTILIANO. (1920). Institutio Oratoria (Harold Edgeworth Butler, trad.). Cambridge: Harvard University Press.

RAPPLE, Brendan. (1989). "Matthew Arnold and Comparative Education”. British Fournal of Educational Studies, 37(1), 54-71. https://doi.org/10.1080/00071005 .1989 .9973797

REAL ACADEMIA ESPAÑOLA. (2005). Diccionario de la lengua española, 23a edición [versión 23.4 en línea]. Recuperado el 16 de marzo de 2020 de https://dle.rae.es SETTIS, Salvatore. (2010). Warburg Continuatus. Descripción de una biblioteca. Madrid: Ediciones de la Central, Museo Nacional de Arte Reina Sofía.

STEINER, George. (1997). Pasión intacta. Ensayos 1978-1995. Madrid: Siruela.

TAVANI, Elena. (2018). "Aby Warburg: Simbolica mimetica e psicotecnica della distrazione”. En Alice Barale, Frabrizio Desideri y Silvia Ferretti (ed.), Energia e reppresentazione. Warburg, Panofsky, Wind. Milano: Mimesis. 85-103.

TÖтÖSY, Steven. (1999). "From Comparative Literature Today Toward Comparative Cultural Studies." CLCWeb: Comparative Literature and Culture, 1(3). https:// doi.org/10.7771/1481-4374.1041

Treml, Martin; FlaGH, Sabine; SGHneIDER, Pablo. (2014). Warburgs Denkraum: Formen, Motiven, Materialen. München: Trajekte.

WARBUrG, Aby. (2004). El ritual de la serpiente. México: Sexto Piso.

WARBURG, Aby. (2005). El renacimiento del paganismo. Madrid: Alianza.

WARBURG, Aby. (2015). Fragments sur l'expression (Susane Müller, dir.). París: L'écarquillé.

WELLEK, René. (1959). “The Crisis of Contemplative Literature”. En David Damrosch, Natalie Melas y Mbongiseni Buthelezi (eds.), The Princeton Sourcebook in Comparative Literature. Princeton: Princeton University Press. 160-172.

WELLEK, René; WARREN, Austin. (1949). Theory of Literature. Nueva York: Harcourt, Brace and Company.

ZUMBUSGH, Cornelia. (2004). Wissenschaft in Bildern: Symbol Und Dialektisches Bild in Aby Warburgs Mnemosyne-atlas Und Benjamins Passagen-werk. Berlín: De Gruyter. 